\title{
A pandemia Covid-19 como pedagogia neoliberalizante no Brasil
}

\section{The Coronavirus and the pedagogy of neoliberalization in Brazil}

\author{
Deborah Werner ${ }^{1}$ \\ Clarice Rocha ${ }^{2}$
}

\begin{abstract}
Resumo: O advento da Covid-19 evidencia a relevância do Estado enquanto agente primordial para o enfrentamento da crise econômica e sanitária instaurada pelos efeitos da pandemia, assegurando condições mínimas necessárias de consumo e bem-estar durante o período de isolamento social, perspectiva contraditória ao papel atribuído ao Estado ao longo do processo de neoliberalização em curso no Brasil desde a década de 1990. A despeito disso, as políticas públicas para a contenção do vírus revelam a prevalência das prerrogativas neoliberais, aspectos analisados à luz da implementação do Auxílio Emergencial, por meio da Lei n 13.982 de 2020, que confere uma renda básica emergencial às famílias de baixa renda.
\end{abstract}

Palavras-chave: Auxílio Emergencial. Coronavírus. Estado. processo de neoliberalização.

Abstract: The advent of the Covid-19 highlights the relevance of the State as the main agent for the confrontation of the economic and sanitary crisis established by the effects of the pandemic, ensuring the minimal necessary conditions of consumption and welfare during the period of social isolation. This perspective confronts to the role assigned to the State over the neoliberalization ongoing process, in progress in Brazil since the decade of 1990. Despite that, the public policies for the contention of the virus reveal the neoliberal prerogatives prevalence, aspects analyzed from the implementation of the Emergency Aid, through the Law n. 13.982 of 2020, which confers an emergencial basic income to the families of low income.

Keywords: Coronavirus. Emergency Aid. Process of neoliberalization. State.

\section{Introdução}

O presente ensaio analisa a implementação do Auxílio Emergencial no Brasil, objeto da Lei $\mathrm{n}^{\circ}$ 13.982, de 2020, que trata das medidas de proteção social implementadas durante o período de enfrentamento da pandemia do coronavírus (Covid-19). Na contramão do ideário neoliberal, o contexto de pandemia evidenciou a relevância da ação do Estado para conter os impactos da crise econômica e

\footnotetext{
${ }_{1}^{1}$ Professora Adjunta do Instituto de Pesquisa e Planejamento Urbano e Regional, da Universidade Federal do Rio de Janeiro (IPPUR/UFRJ). Doutora em Planejamento Urbano e Regional, pela UFRJ. E-mail: deborahwerner@ippur.ufrj.br.

2 Pesquisadora de Iniciação Científica e graduanda do curso de Gestão Pública para o Desenvolvimento Econômico e Social (GPDES/IPPUR/UFRJ).E-mail: clariceufrj@gmail.com.
} 
sanitária que acomete as sociedades, revelando a importância do papel das políticas públicas e a ineficácia das políticas neoliberais para o bem-estar e alcance das potencialidades dos indivíduos e sociedades.

Em meio à pandemia, vários países têm acionado políticas fiscais, monetárias e creditícias para garantir as mínimas condições de demanda efetiva devido ao grau elevado de incerteza e de preferência pela liquidez aos moldes de Keynes (1936), provocadas pelo contexto pandêmico e de isolamento social. A questão que se coloca neste ensaio é se essas ações promoverão uma ruptura nas prerrogativas neoliberais ou se são apenas um interregno justificado pela pandemia, que requer a ação do Estado e é tratada como excepcionalidade, cabível sob o arcabouço neoliberal.

O caso brasileiro sugere, com base nas ações do governo federal, o caráter excepcional que se deseja conferir à ação estatal, permitindo a continuidade da rota neoliberal após o contexto pandêmico e contrariando qualquer previsão de um novo normal pós-pandemia capaz de romper com as prerrogativas da neoliberalização. O artigo é elaborado em três seções, além desta introdutória e da última, conclusiva. A primeira seção discute o processo de neoliberalização, em termos econômicos e ideológicos, e suas implicações no caso brasileiro; a segunda seção argumenta a implementação do auxílio emergencial de $\mathrm{R} \$$ 600,00 às famílias enquanto uma pedagogia neoliberal, que reforça e promove os valores dessa corrente econômico-ideológica; e a terceira seção ensaia elementos estruturais a serem considerados para a superação da ofensiva neoliberalizante.

\section{Processo de neoliberalização e implicações no Brasil}

O pensamento neoliberal tem como pressuposto a crença nos mercados abertos, competitivos e não regulados, não submetidos a ingerências estatais nem a ações de coletivos sociais, considerados um mecanismo ótimo para o desenvolvimento econômico. Trata-se de uma visão utópica da supremacia dos mercados e da redução do papel do Estado, visão enraizada em uma concepção de individualismo competitivo que refuta as distintas formas de solidariedade social e institucional, na busca pela comodificação crescente de amplos domínios da vida social, por meio de instrumentos financeiros especulativos e de abertura de novas frentes de lucros aos detentores de capital (BRENNER et al., 2012; PECK e THEODORE, 2019).

O processo de neoliberalização nunca se manifesta em uma forma pura, como um todo regulatório abrangente, conforme almeja seu arcabouço teórico. As tendências de neoliberalização somente podem ser articuladas em modalidades incompletas, híbridas, que podem se cristalizar em certas formações regulatórias, mas que são, não obstante, contínuas e ecleticamente retrabalhadas de maneiras contextualmente específicas. Como consequência, em termos globais, o processo jamais conquista a totalidade do sistema, mas opera dentro dele e cria um mundo de diversidade e desigualdade, obedecendo ao desenvolvimento desigual do próprio capitalismo (HALL et al., 2015; PECK e THEODORE, 2019; SMITH, 1988).

O processo não se limita às relações econômicas entre Estado e mercado, mas funda-se, como todo acordo social, na incorporação do senso comum, entendido como um conjunto de crenças e ideias 
enraizadas desde a escala do indivíduo. O senso comum neoliberal baseia-se na suposta naturalidade do mercado, na primazia do indivíduo e na superioridade do privado sobre o público, aspectos capazes de envolver econômica e ideologicamente populações inteiras em uma visão de mundo financeirizada e mercantilizada (HALL et al., 2015).

Conforme os autores, a ideologia do individualismo impôs a estigmatização dos chamados "pobres indignos", demandantes de assistência social que, supostamente, preferem viver à custa de quem trabalha ou dos benefícios, como um estilo de vida. Em contraposição, ressalta a ideia do empreendedor, da celebridade instantânea, do self-made man como formas de reconhecimento do sucesso individual com base na competição. Ao legitimar ideologicamente a lógica da maximização e do capital sobre as demais esferas da vida, escamoteia a interdependência dos sujeitos e fragiliza valores de igualdade, democracia e cidadania. A ideologia neoliberal, transmitida por redes hegemônicas de think tanks, agendas políticas, universidades, institutos de pesquisa, entre outros meios, exerce papel pedagógico em disseminar, legitimar e revigorar valores, discursos e práticas neoliberais que se enraízam como senso comum popular, aceito de forma inquestionável. $\mathrm{Na}$ condição de visão de mundo, portanto, é capaz de definir parâmetros para as discussões públicas, debates na mídia e concepções dos indivíduos (HALL et al., 2015; MACRINE, 2016).

Apesar dos resultados de quatro décadas de neoliberalização - com concentração de renda e riqueza, desigualdades econômicas, sociais e políticas, crise ambiental e ataque aos padrões de vida dos menos favorecidos, entre outras consequências - HALL et al. (2015) afirmam que ainda existe consenso social e político em torno da validade do receituário neoliberal, pois as próprias crises são utilizadas para reforçar a redistribuição dos pobres para os ricos e proporcionam o álibi para avançar e ampliar a reestruturação do Estado e da sociedade em prol dos mercados. Por meio de uma série de reformas ideologicamente orientadas e projetadas para avançar a privatização e a comodificação, o ideário neoliberal promove soluções privadas e individualizadas (sucesso individual, empreendedorismo, meritocracia) para resolver problemas que concernem à coletividade. Nesse sentido, as soluções para as crises derivadas do modelo neoliberal não passam pela ruptura com suas diretrizes, mas concorreram para sucessivas rodadas de neoliberalização, as quais destroem arcabouços precedentes e criaram formas institucionais e regulatórias que se imbricaram com as já conhecidas trajetórias, o que faz da neoliberalização um processo historicamente constituído e dependente de contextos históricos e políticos específicos (BRENNER et al., 2012; PECK, 2010). A crise de 2008 e as medidas de enfrentamento nos países da Zona do Euro exemplificam esse processo (HALL et al., 2015).

No Brasil, as rodadas de neoliberalização iniciaram-se na década de 1990 e promoveram mecanismos e instrumentos de experimentações re-regulatórias sobre as três mercadorias fictícias: terra, capital e trabalho (BRANDÃO, 2017). A manutenção da macroeconomia financeira (PAULANI, 2017), a estrutura tributária regressiva (RECEITA FEDERAL, 2017) e os determinantes da desindustrialização e da especialização primário-exportadora (CANO, 2017) revelaram as contradições da estratégia inaugurada em 2003, que tentara conciliar políticas de crescimento econômico e distribuição de renda, com a agenda neoliberal. Os governos Michel Temer (2016-2018) e Jair Bolsonaro (2018-2022) intensificaram as rodadas de neoliberalização. Entre as ações de desmonte do Estado e das políticas públicas, destacam-se: cortes 
orçamentários em gastos primários como saúde e educação, sobretudo com a Emenda Constitucional 9533; reformas trabalhista e previdenciária, que significaram perdas de direitos históricos da classe trabalhadora brasileira; ode ao empreendedorismo como solução ao desemprego elevado; cortes no Programa de transferência de renda, o Bolsa Família $(\mathrm{BF})$; retrocesso no programa habitacional Minha Casa Minha Vida; desmonte da política de universalização do Ensino Superior, iniciativas de privatização dos serviços públicos, como o Future-se, e o PL n 4162/2019, referente à privatização do saneamento básico (CONGRESSO EM FOCO, 2020; BRASIL DE FATO, 2019a; BRASIL DE FATO, 2019b; BRASIL DE FATO, 2020; MEC, 2020).

A justificativa para tais medidas foi solucionar a crise decorrente do dirigismo estatal dos governos petistas e da elevação dos gastos primários, sobretudo no governo Dilma Rousseff, aspecto refutado por Herman e Gentil (2017) e Dweck et al. (2018), entre outros, os quais, com base em dados, evidenciam que as políticas de austeridade fiscal, em um momento de retração dos demais componentes da demanda efetiva, justificam a desaceleração cíclica, somadas às condições do mercado externo.

É, portanto, em meio ao aprofundamento das medidas neoliberalizantes e elevadas taxas de desemprego, informalidade e desalento (IBGE, 2019; PNAD CONTÍNUA, 2020) que a pandemia do Covid-19 chega ao Brasil. Reveladora das contradições entre tais paradigmas e as aspirações de bem-estar e desenvolvimento, poderia significar a ruptura com o modelo em curso. No entanto, o que se verifica, com base no modo de implementação das medidas de enfrentamento da pandemia, é a tendência de aprofundamento, e não de ruptura, da ofensiva neoliberal - aspectos a serem tratados com a implementação do Auxílio Emergencial às famílias.

\section{O auxílio emergencial como pedagogia neoliberalizante}

A possibilidade de adoção de medidas para o enfrentamento da Covid-19 foi objeto da Lei $n^{\circ}$ 13.979, de 6 de fevereiro de 2020, que reconhece a pandemia como uma questão de saúde pública de importância internacional e estabelece, entre as possíveis medidas, o isolamento social e a quarentena ${ }^{4}$. Em 18 de março de 2020, o Congresso Nacional estabeleceu o Decreto $\mathrm{n}^{\circ}$ 6, que reconheceu o estado de calamidade pública no Brasil, para fins da Lei Complementar n 101, de 2000, Lei de Responsabilidade Fiscal, o que permitiria a flexibilização das regras fiscais em função das medidas para o enfrentamento da pandemia 5 .

Uma vez que os Estados adotaram o isolamento social e diante da inviabilidade de manutenção de diversas atividades econômicas, tornou-se consenso entre economistas, políticos e sociedade civil a necessidade de medidas de proteção social e de minimização dos efeitos da pandemia na demanda efetiva.

\footnotetext{
${ }^{3}$ O Novo Regime Fiscal aprovado em 2016 congela gastos públicos primários por 20 anos. Disponível em: $<$ http://www.planalto.gov.br/ccivil 03/constituicao/Emendas/Emc/emc95.htm>

${ }^{4}$ Disciplinada pela Portaria n³56, do Ministério da Saúde, de 11 de março de 2020.

${ }^{5}$ Entre a Lei $n^{\circ} 13.979$ e o Decreto ${ }^{\circ} 6$, ocorreram as festividades carnavalescas.
} 
No rol dessas medidas ${ }^{6}$, o Auxílio Emergencial foi aprovado pela Câmara dos Deputados, em 26 de março de 2020, após ampla articulação da sociedade e por meio da Campanha "Renda básica que queremos", que envolveu a Rede Brasileira de Renda Básica de Cidadania, parlamentares e sociedade civil (WERNER e ROCHA 2020). Em contraposição à proposta do Governo Federal, de auxílio mensal de R $\$ 200,00$, por três meses, o projeto foi aprovado no Congresso Nacional com o valor de $\mathrm{R} \$ 600,00$ e sancionado pelo Presidente Bolsonaro (sem partido) em $1^{\circ}$ de abril de 2020, objeto da Lei $\mathrm{n}^{\circ} 13.982^{7}$, com posteriores vetos, pela Lei n 13.998, de 2020, incluindo a ampliação de categorias profissionais, aprovada na Câmara (EBC, 2020a).

Entre a aprovação da medida e a liberação do benefício, ressaltam-se vários impasses. O primeiro foi a alegação por parte do Ministro da Economia Paulo Guedes de que a aprovação levaria o governo a uma insegurança jurídica ao autorizar o gasto, por conta da Lei de Responsabilidade Fiscal e da EC 95, pela falta de fontes orçamentárias (REDE BRASIL ATUAL, 2020). A oposição alegava que a flexibilização da Lei de Responsabilidade Fiscal, autorizada pelo Supremo Tribunal Federal (STF), pelo Decreto Legislativo $\mathrm{n}^{\circ}$ 6, seria suficiente para o pagamento do auxílio. Conduzido dessa maneira, o impasse deixou milhões de brasileiros aguardando uma resolução atinente à própria sobrevivência durante a pandemia.

Outro impasse ocorreu em torno do acesso ao benefício. A Caixa Econômica Federal (CEF) criou o aplicativo para os que não estavam registrados no Cadastro Único, mas essa iniciativa resolveu apenas parcialmente o problema, visto que parcela da população potencialmente elegível tem acesso restrito ou não tem acesso digital (G1, 2020b). Além disso, a exigência de regularização do CPF para recebimento do auxílio transformou-se em outra dificuldade, o que suscitou a judicialização do processo de concessão do benefício. Ambas as situações geraram aglomerações nas agências bancárias e na Receita Federal, contrariando a necessidade de isolamento social para a população vulnerável dependente do auxílio (UOL, 2020a; G1, 2020c).

A demora para implementar o auxílio e a fiscalização revelaram a vulnerabilidade econômica e social a que foi submetida metade da população brasileira, demandante do auxílio (G1, 2020 a; EBC, 2020b), bem como o caráter coercitivo para a liberação do benefício, ao priorizar o controle de fraudes em detrimento da urgência em prover as famílias do mínimo necessário para a sobrevivência durante a pandemia. As possíveis fraudes, as quais, sem dúvida, devem ser coibidas, poderiam ser investigadas ao longo da implementação ou mesmo após o fim do estado de calamidade. Em nome das condições fiscais, tal condição suscitou a penalização e a submissão de famílias, sobretudo aquelas em situação de vulnerabilidade, à agonia e à destituição material.

\footnotetext{
${ }^{6}$ Ainda que não sejam objeto do artigo, ressaltam-se as seguintes: Medida Provisória (MP) no 927, de 22 de março de 2020, referente às medidas trabalhistas; MP $\mathrm{n}^{\circ} 936$, de $1^{\circ}$ de abril de 2020, referente ao Programa Emergencial de Manutenção do Emprego e da Renda; MP n ${ }^{\circ}$ 944, de 3 de abril de 2020, que instituiu o Programa Emergencial de Suporte a Empregos; e a Lei n ${ }^{\circ} 13.999$, de 18 de maio de 2020, sobre o Programa de Apoio às Micro e Pequenas Empresas (Pronampe).

${ }^{7}$ Sobre o auxílio emergencial, ver https://auxilio.caixa.gov.br/\#/inicio.
} 
O tempo de duração do benefício também é questionável: as incertezas causadas pela pandemia não permitem garantir que, em três meses, as atividades econômicas poderão voltar ao padrão anterior. $\mathrm{O}$ medo, a possível instabilidade na condição financeira das famílias para retomar os padrões de consumo, novos hábitos, as incertezas dos empresários em investir, entre outros aspectos, fazem que a dinâmica econômica, já reprimida antes mesmo da pandemia, não seja retomada. No entanto, mediante o debate em torno da prorrogação do auxílio emergencial, o governo avalia a redução do valor das parcelas, valendo-se da justificativa de impossibilidade fiscal (G1, 2020c).

Todos esses impasses legitimaram a falsa dicotomia entre economia e saúde, e suscitou pressão pela flexibilização do isolamento social, ocorrida em vários Estados (BBC, 2020). Tal flexibilização expõe, sobretudo, os trabalhadores informais, aqueles em contratos precários, sem renda fixa e sem auxílio emergencial e os pequenos negócios, como se não houvesse outra solução que não a individual, a atividade laboral e empresarial, como fonte de renda. Corrobora-se, portanto, a ideia de Estado ineficiente, moroso, sem recursos, em conformidade com o padrão ideológico do processo de neoliberalização e consolidam-se o senso comum e a pedagogia neoliberal. No entanto, evidencia-se que os entraves impostos à ação do Estado são regulatórios e não de escassez de recursos, como deixou claro a flexibilização da Lei de Responsabilidade Fiscal, após a declaração do estado de calamidade, ao permitir à União descumprir metas fiscais estabelecidas pela Emenda Constitucional 95 até 31/12/2020.

Verifica-se que desde o início da pandemia, as ações e omissões governamentais têm promovido uma cisão entre aqueles que podem e os que não podem ficar em isolamento, de modo a reproduzir o padrão de privilégios que marca a sociedade brasileira, reiterando o aparato político e ideológico neoliberal. Escamoteia-se o fato de que a renda emergencial não é apenas uma questão ética e humanitária em contexto de pandemia, mas também favorável à recuperação econômica, ao garantir o consumo de bens de primeira necessidade às famílias e promover efeitos multiplicadores via gastos públicos. Considerando a capacidade ociosa e a contração da demanda, caracterizadores de contextos de recessão, preocupações em torno da inflação também não se confirmam.

Não basta, portanto, uma pandemia para se romper com o ideário neoliberal, como revela a posição do Ministro Paulo Guedes, cuja alegação é de que o Estado quebrou e que investimentos estatais são equívocos do passado (UOL, 2020b). Os dispositivos ideológicos e pedagógicos do neoliberalismo encontram, nas crises, justificativas para sua própria defesa e fortalecimento. A situação brasileira indica, de um lado, a precariedade econômica e social após anos de neoliberalização econômica e, de outro, a resistência para romper com o processo de neoliberalização e promover políticas públicas de bem-estar social, ao reforçar o senso comum neoliberal de ausência e ineficiência do Estado e construir os caminhos discursivos para novas rodadas de políticas de austeridade fiscal, sob a justificativa dos gastos realizados para conter o efeito da pandemia. 


\section{A agenda pós-pandemia: a utopia a ser perseguida}

É necessária a alteração de aspectos não apenas conjunturais, a partir da pandemia, e também o reconhecimento dos elementos estruturais determinantes de uma sociedade brasileira tão desigual. Por esse aspecto, o consenso formado em torno da Renda Básica Emergencial durante a vasta disseminação da Covid-19 permite um debate mais amplo sobre a necessidade de uma Reforma Tributária mais justa, que rompa com o seu caráter regressivo e propicie o uso do fundo público para políticas públicas orientadas ao bem-estar (educação, saúde, infraestrutura, ciência e tecnologia etc.). A reversão desse quadro exige a promoção de uma estrutura tributária mais justa e equitativa, pautada na tributação de dividendos de pessoas físicas, heranças, grandes fortunas e propriedades. Essas bases permitiriam ampliar a arrecadação no Brasil. A defesa da Reforma Tributária progressiva justifica-se, ainda, em razão do caráter político e conflituoso, em termos de poder de classe, expresso na estrutura tributária.

As mudanças no mercado de trabalho independem da emergência pandêmica e relacionam-se, de um lado, às transformações tecnológicas do capitalismo contemporâneo, cuja adesão tende a se intensificar com a pandemia e, de outro lado, à permanente precarização e informalidade do setor terciário no Brasil. Tais mudanças requerem a oferta de fontes de renda que independam do trabalho, ao lado da provisão de serviços públicos, capazes de diminuir a desigualdade de renda e de acesso aos serviços essenciais, de modo a resgatar o papel atribuído ao Estado: redistributivo e provedor de bem-estar.

Outro elemento que precisa ser ressaltado como enfrentamento à ofensiva neoliberal é a revogação da Emenda Constitucional n ${ }^{\circ}$ 9. Em tempos de neoliberalização, o Estado brasileiro tem sido "Estado máximo", em favor da acumulação de capital e das altas rendas, e "Estado mínimo", para enfrentar as desigualdades históricas da sociedade brasileira, restringindo suas ações, perante as classes populares, ao poder coercitivo de fisco e de polícia.

Somam-se às questões fiscais e tributárias as mudanças na estrutura produtiva e na inserção internacional: a necessidade de garantir insumos fármacos, equipamentos e instrumentos hospitalares em função da pandemia, e vis-à-vis à restrição de fluxos internacionais, exige políticas de reconversão industrial e revela a vulnerabilidade promovida pela desindustrialização e reprimarização da pauta exportadora aspectos que requerem o resgate de uma política orientada para a industrialização e inovação. Acoplado a uma estratégia geopolítica, tal intento, além de instituir uma tendência de superação da reprimarização, galgaria o reposicionamento do país no cenário político internacional, assentado em preceitos científicos e no desenvolvimento tecnológico que são liderados pela imensa rede pública produtora de ciência nele existente.

\section{Considerações finais}

A lição em decorrência da pandemia Covid-19 é a necessidade de ruptura com as políticas neoliberalizantes em curso no país e o resgate do papel conferido ao Estado Brasileiro de assegurar o "bem-estar, o desenvolvimento, a igualdade e a justiça", valores expressos na Carta Magna de 1988 e que 
foram subordinados à pauta financeira e rentista imposta ao país há mais de três décadas. Momentos de crise podem ser uma oportunidade para a implementação de políticas inovadoras que apontem um caminho para transformações perenes. Para tanto, além das transformações na base material, é necessário enfrentar a disputa de narrativas que emergem em defesa do receituário neoliberal e em defesa da austeridade fiscal já presente, como se verifica na implementação do Auxílio Emergencial. O enfrentamento conjuntural deve-se somar ao enfrentamento das questões estruturais, pois nada impede que os neoliberais, hoje defensores da ação estatal, retomem seus dogmas assim que se encerrar o estado de calamidade.

\section{Referências}

AGÊNCIA IBGE. PNAD Contínua. 21/03/2020 Disponível em https://tinyurl.com/pnadcontinua. Acesso em abril de 2020.

BBC. Na contramão do mundo, Brasil flexibiliza quarentena antes de atingir pico de mortes. Disponível em https://www.bbc.com/portuguese/brasil-52930843. Acesso em maio de 2020.

BRANDÃO, C. Crise e rodadas de neoliberalização: impactos nos espaços metropolitanos e no mundo do trabalho no Brasil. Cadernos Metrópole, 19 (38), 45-69, 2017. Disponível em

https://tinyurl.com/rodadasdeneoliberalizacao. Acesso em maio de 2018.

BRASIL DE FATO (a). Governo Bolsonaro corta R \$ 1,9 bilhão do "Minha Casa Minha Vida" para 2020. 03/09/2019. Disponível em: https://tinyurl.com/minhacasaminhavida2020. Acesso em março de 2020.

BRASIL DE FATO (b). PL que permite privatização dos serviços de saneamento pode ser votada nesta quarta. 22/06/2020. Disponível em https://tinyurl.com/plprivatizacao. Acesso em junho de 2020.

BRENNER, N.,PECK, J., \& THEODORE, N. (2012) Após a neoliberalização?. Cadernos Metrópole, 14(27). Disponível https://revistas.pucsp.br/metropole/article/view/14779 Acesso em setembro de 2016.

CANO, W. Brasil: construção e desconstrução do desenvolvimento. Texto para Discussão 304. Unicamp, 2017. Disponível em https://tinyurl.com/canodesenvolvimento. Acesso em maio de 2020.

CONGRESSO EM FOCO. Com Crise e cortes no Bolsa Familia, 3 milhões entram na extrema pobreza. 04/03/2020. Disponível em: https://tinyurl.com/congressoemfoco. Acesso em março de 2020.

DWECK, E; OLIVEIRA, A. L.M. de; ROSSI, P.. Austeridade e Retrocesso: Impactos Sociais da Política Fiscal no Brasil. São Paulo: Brasil Debate e Fundação Friedrich Ebert, 2018.

EMPRESA BRASILEIRA DE COMUNICAÇÃO (EBC) (a). Bolsonaro sanciona com 11 vetos lei que altera auxílio emergencial. 15/05/2020. Disponível em https://tinyurl.com/11vetosauxilioemergencial. Acesso em junho de 2020.

EMPRESA BRASILEIRA DE COMUNICAÇÃO (EBC) (b). Em dois meses, 107 milhões de brasileiros pediram auxílio emergencial. Disponível em https://tinyurl.com/107milhoespedemauxilio. Acesso em junho de 2020.

G1, 2020 (a). Auxílio emergencial de 96,9 milhões de cadastrados. 01/05/2020. Disponível em https://tinyurl.com/505milhoesaprovados. Acesso em maio de 2020. 
G1. (b) Em 2018, quase 46 milhões de brasileiros ainda não tinham acesso à internet, aponta IBGE. 29/04/2020. Disponível em https://tinyurl.com/acessoainternet. Acesso em maio de 2020.

G1 (c). União não aguenta, diz Bolsonaro sobre prorrogação do auxílio emergencial. 22/06/2020. Diponível em https://tinyurl.com/prorrogacaoauxilio. Acesso em junho de 2020.

GENTIL, D.; HERMANN, J.. A política fiscal do primeiro governo Dilma Rousseff: ortodoxia e retrocesso. Economia e Sociedade, 2017.

HALL, S. MASSEY, D. RUSTIN, M. After neoliberalism: analysing the present. IN: After Neoliberalism: THE KILBURN MANIFESTO Stuart Hall, Doreen Massey \& Michael Rustin (Orgs.). London Lawrence \& Wishart, 2015.

INSTITUTO BRASILEIRO DE GEOGRAFIA E ESTATÍSTICA (IBGE) Desemprego. Disponível em https://www.ibge.gov.br/explica/desemprego.php.

KEYNES, J.M. A Teoria Geral do Emprego, do Juro e da Moeda. São Paulo, Editora Nova Cultural, 1996.

MACRINE, S. L.. Pedagogies of Neoliberalism. In S. Springer, K. Birch \& J. MacLeavy (Eds.), The Handbook of Neoliberalism (Ch. 26, pp. 294-305). New York, NY: Routledge, 2016.

MINISTÉRIO DA EDUCAÇÃO (MEC). Future-se Disponível em http://portal.mec.gov.br/component/tags/tag/52641) Acesso em maio de 2020.

PECK., J.; THEODORE, N. Still neoliberalismo? The South Atlantic Quarterly 118:2, Duke University Press, April 2019.

PECK, J. (2010). Constructions of neoliberal reason. Oxford: Oxford Scholarship, 2010.

PAULANI, L. A experiência brasileira entre 2003 e 2014: Neodesenvolvimentismo? Cadernos do Desenvolvimento, Rio de Janeiro, v. 12, n. 20, pp. 135-155, jan.-jun, 2017.

RECEITA FEDERAL. Carga Tributária no Brasil, 2017. Análise por Tributos e Bases de Incidência. Ministério da Fazenda. Receita Federal, 2018.

SMITH, N. Desenvolvimento Desigual: natureza, capital e a produção do espaço. Trad. Eduardo de Almeida Navarro. Rio de Janeiro: Bertrand Brasil,1988.

UOL (a). Centralizar auxílio de $\mathrm{R} \$ 600$ na Caixa criou fila e atraso dizem especialistas. Disponível em https://tinyurl.com/caixacriafilaeatraso. Acesso em maio de 2020.

UOL. 2020 (b). Reunião Ministerial: governo quebrou, diz Paulo Guedes. 22/05/2020. Disponível em https://www.youtube.com/watch?v=kOyS9f2WJOc. Acesso em maio de 2020.

WERNER, D.; ROCHA, D. Do desalento a busca por novos caminhos. Boletim IPPUR. 13/04/2020. Disponível em https://tinyurl.com/dodesalentoabuscapornovoscam. Acesso em abril de 2020. 